International Journal of Current Advanced Research

ISSN: O: 2319-6475, ISSN: P: 2319 - 6505, Impact Factor: SJIF: 5.995

Available Online at www.journalijcar.org

Volume 6; Issue 3; March 2017; Page No. 2421-2428

DOI: http://dx.doi.org/10.24327/ijcar.2017.2428.0020

Research Article

\title{
PERSONALIZED NICHE ONLINE MARKETING TO GENERATE AND SUSTAIN E-LOYALTY AMONG THE MILLENNIAL GENERATION
}

\author{
Aparna P. Goyal*
}

F-3 Block 3rd Floor | Amity University Campus Sector - 125, Noida - 201 313. UP, INDIA

\begin{tabular}{|c|c|}
\hline 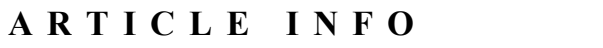 & $A B S T A C T$ \\
\hline $\begin{array}{l}\text { Article History: } \\
\text { Received } 10^{\text {th }} \text { December, } 2016 \\
\text { Received in revised form } 7^{\text {th }} \text { January, } 2017 \\
\text { Accepted } 11^{\text {th }} \text { February, } 2017 \\
\text { Published online } 28^{\text {th }} \text { March, } 2017\end{array}$ & $\begin{array}{l}\text { The present study explored the association between the intensity of online digital marketing } \\
\text { tools use for online loyalty (Customer Retention) and the business performance satisfaction } \\
\text { of Thai microenterprises. The survey data were collected from } 217 \text { owners of the small } \\
\text { shops at major marketplaces in NCR, India. The results from partial least square regression } \\
\text { analysis showed that the SME Owners who used online digital marketing tools intensively } \\
\text { for loyalty tended to report higher satisfaction with their business performance. }\end{array}$ \\
\hline $\begin{array}{l}\text { Kye Words: } \\
\text { - E-loyalty } \\
\text { - Online digital marketing tools marketing; } \\
\text { - SME } \\
\text { - Social competency; } \\
\text { - Media Tools } \\
\text { - Online Consumer Behaviour }\end{array}$ & $\begin{array}{l}\text { Furthermore, the results from the moderating effect analyses found that the positive } \\
\text { relationship between online digital marketing tools use intensity for loyalty and business } \\
\text { performance satisfaction tended to be significantly higher for the SME Owners who } \\
\text { exhibited lower levels of social competency in business, as well as for the companies that } \\
\text { generated more sales from online digital marketing tools. The main findings of this } \\
\text { research provide practical implications for microenterprise SME Owners. Given that } \\
\text { communication in online digital marketing tools tends to involve less interpersonal } \\
\text { interactions than face-to-face communication, using online digital marketing tools for } \\
\text { loyalty activities might be essential in enabling SME Owners with low social competency } \\
\text { to interact with customers to improve customer satisfaction. Also, this finding implies that } \\
\text { using online digital marketing tools for loyalty tends to be more crucial for companies that } \\
\text { primarily target customers who are online digital marketing tools users. }\end{array}$ \\
\hline
\end{tabular}

Copyright $₫ 2017$ Aparna P. Goyal. This is an open access article distributed under the Creative Commons Attribution License, which permits unrestricted use, distribution, and reproduction in any medium, provided the original work is properly cited.

\section{INTRODUCTION}

High competitive rivalry among existing firms, the unpredictable changes in consumption trends, and more sophisticated customer demands cause urge for high customer loyalty. Unarguably, the ability of firms to generate and sustain customer satisfaction is the key indicator that can strongly determine the success of the business. In order to create and maintain competitiveness to outperform other competitors, it is necessary for the companies to strive to provide superior service to customers, to increase customer satisfaction. To achieve this task effectively, it is crucial for the companies to accurately understand and discover the needs and wants of the customers, and be able to tailor the products/services to meet or exceed customers' expectations. In particular, the marketing practice known as online loyalty (Customer Retention) is often suggested to enable companies to achieve this objective. While the traditional loyalty, implemented through computerized software and database systems, is commonly adopted by large corporations, there is evidence that online digital marketing tools such as Facebook

*Corresponding author: Aparna P. Goyal

F-3 Block 3rd Floor | Amity University Campus Sector - 125, Noida - 201 313. UP, INDIA and Instagram have also become an emerging trend in facilitating the implementation of loyalty activities by small firms (Malthouse et al., 2013; Trainor et al., 2014; Woodcock et al., 2011). Although the topic of online digital marketing tools use for loyalty has already appeared in the literature, as yet the application of online digital marketing tools for loyalty in microenterprises has not been adequately explored. Given that the characteristics of microenterprises are different from medium and large enterprises, their adoption of online digital marketing tools for loyalty might follow patterns which differ from the models and theories put forward for large enterprises (Harrigan, Ramsey, \& Ibbotson, 2009). Also, the issue of whether the adoption of online digital marketing tools for loyalty can be linked to better company performance has not been previously explored. These are the main research questions that this research aims to address. This research not only discusses how online digital marketing tools can be used as the loyalty tool for microenterprises, but the authors also empirically investigate the association between the intensity of online digital marketing tools use for loyalty and business performance satisfaction, using a sample from the microenterprises in NCR, India. In particular, NCR, India serves as a suitable research context for studying online digital marketing tools application in business, given that 
online digital marketing tools have been extensively used by many small firms as a key channel to advertise and sell their products (Quevedo, 2012). However, although the issue about the benefits of online digital marketing tools use in business has been previously investigated (Trainor, 2013; Trainor et al., 2014), existing studies have only focused on the contributions of online digital marketing tools use to the outcome variables, without considering the role of the entrepreneur and the firm's characteristics, which can moderate the benefits that companies can obtain from online digital marketing tools application. While online digital marketing tools use for loyalty may generally benefit firms' performance satisfaction, it is possible that the benefits could be more prominent for SME Owners who lack the social competency to interact face-to-face with customers in the bricks-and-mortar business environment, as well as for firms that rely more intensively on online digital marketing tools sales. The existing support for the moderating roles of SME Owners and firms' characteristics will be discussed in the following section.

In a general sense, loyalty can refer to the utilization of customer-related information or knowledge to deliver relevant products or services to consumers, in order to improve customer retention through the effective management of customer relationships (Bull, 2003; Levine, 2000). Ryals and Payne (2001) argued that although the term "loyalty" has normally been used interchangeably with "relationship marketing", one particular point that distinguishes loyalty from relationship marketing is that loyalty involves the utilization of information technology (e.g., computer software, database systems) to facilitate the relationship marketing process. Because of this, Payne and Frow (2005, p. 167) suggested that "loyalty is more commonly used in the context of technology solutions and has been described as information-enabled relationship marketing".

In the literature to date, the majority of research on loyalty has explored the implementation of loyalty by large and medium companies, but fewer studies have focused on microenterprises. In fact, some evidence shows that smaller and larger companies tend to emphasize online digital marketing tools applications in different areas. Verheyden and Goeman (2013) found that both small companies and large corporations have increasingly begun to apply online digital marketing tools to add value to their businesses. However, when comparing the applications of online digital marketing tools between small and large companies in the four areas of value creation (internal communication, external communication, knowledge sharing, and recruitment), it seems that small companies tended to utilize online digital marketing tools more for external communication, while large corporations tended to use them more extensively for internal communication (Verheyden \& Goeman, 2013). As organizational theories and practices implemented by large organizations may not reflect the true structure and management principles of small organizations (Harrigan et al., 2009), it is important to explore the loyalty practices of microenterprises that may be constrained by their unique characteristics. Generally, microenterprises are tiny businesses that employ fewer than ten employees. Sometimes they only have one employee, who is actually the business owner. Due to the size disadvantage, one particular constraint that they normally encounter is a lack of financial capital to support the operations (Kamal, Andre, \& Augustyn, 2011). Moreover, instead of having a management team to perform various business functions such as marketing and technology management, as do medium-sized and large corporations, the owners of microenterprises generally perform these activities themselves. For these reasons, the implementation of loyalty requires significant investment in information technology infrastructure, human resources, and know-how; this is more suited to medium and large firms, and may be difficult for microenterprises to undertake (Garcia, Pacheco, \& Martinez, 2012). As a result, the loyalty implementations by microenterprises tend to differ those of large and mediumsized enterprises. For example, scholars have suggested that while large corporations normally utilize state-of-the-art computerized systems for their loyalty activities, microenterprises tend to rely on basic technologies such as email and simple accounting packages to support their operations (Bharati and Chaudhury, 2006; Kamal et al., 2011).

Recent studies have proposed that online digital marketing tools technology can provide the opportunity for microenterprises to implement loyalty activities (Malthouse et al., 2013; Trainor et al., 2014; Woodcock et al., 2011). However, how microenterprises can utilize online digital marketing tools for loyalty has not been well-documented. In this study, the authors adopt the conceptualization of loyalty activities proposed by Peppers and Rogers (2011) as the framework for online digital marketing tools application for loyalty. In this framework, loyalty activities are classified into four processes, namely identification, differentiation, interaction, and customization. The first process of loyalty, identification, involves collecting customer information, such as demographic characteristics, purchasing history, and personal preferences. The second process, differentiation, aims to segment customers into groups based on similar needs and values. The third process, interaction, involves interacting and communicating with customers to ensure that their expectations are well-understood, in order to aid the development of products and services that create long-term customer satisfaction. The fourth process of loyalty, customization, involves customizing and tailoring marketing offers to each customer according to their specific needs and preferences.

In particular, microenterprises in NCR, India use online digital marketing tools for all four loyalty processes (Quevedo, 2012). First, for the identification process, when a person clicks "Like" on a company's Facebook page or leaves comments about posts, the company can view the profiles of that person and gain access to the information that the person has shared on his/her Facebook page. This function is similar in Instagram; the profiles of a person can be viewed after he/she clicks "Follow" on the company's Instagram page. The customer information that the company obtains from online digital marketing tools is not limited to a person's basic demographic information, but it also encompasses their lifestyle and personal preferences, which can be inferred from the status updates and photos that they post and share publicly on his/her personal online digital marketing tools page, thereby allowing the company to use this information to create the customer database. More importantly, this information is also crucial for the differentiation process of loyalty, because the company can use it to segment customers 
into groups based on similar characteristics and preferences. For the interaction process, the company can use online digital marketing tools as a channel to communicate with customers more effectively through status updates and personalized messages. In addition, the company can also receive feedback from the customer through the comments that they give to the posts on the company's online digital marketing tools page. These feedback systems allow the company to learn more about the needs and preferences of the customers (Castronovo and Huang, 2012; Hennig-Thurau et al., 2010; Trainor et al., 2014). Lastly, online digital marketing tools can be used to facilitate the customization process. Because online digital marketing tools has a function that allows members of the online digital marketing tools page to be assigned to different groups, the information about marketing offers can be customized and then posted to separate member groups, so that the offers match the specific preferences of each customer group. Also, the use of the hashtag (\#) in online digital marketing tools posts can be applied to categorize products, which makes it easy for customers to view products according to their interests.

Similar to the benefits that traditional loyalty provides (Mazurencu et al., 2007; Sasvari and Majoros, 2013), using online digital marketing tools for loyalty can benefit the business performance of microenterprises in many aspects. In particular, the ability of the companies to interact with customers and to customize their marketing communication on a one-to-one basis allows the companies to enhance customer satisfaction and commitment to a long-term relationship. In addition to the benefits that traditional loyalty provides, using online digital marketing tools for loyalty also provides more advantages, because communications in online digital marketing tools can be made in real-time, thereby allowing companies to interact with and respond to customers instantly. Given that the contents posted on online digital marketing tools can be viewed and shared by many online digital marketing tools users, online digital marketing tools marketing can help the companies to promote their products or services, and to expand the market more quickly and economically than by using traditional marketing channels. Using online digital marketing tools as a marketing tool also helps companies to reduce the operating costs normally incurred by traditional marketing channels. In recent research, the contributions of online digital marketing tools are also supported empirically by the study of Trainor et al. (2014), which found that the intensity of online digital marketing tools application in business positively and significantly links to higher financial and non-financial performance.

\section{"SME Owners who use online digital marketing tools more intensively for loyalty will achieve higher business performance satisfaction."}

Although using online digital marketing tools as a loyalty tool can provide benefits that help SME Owners to enhance business performance, the authors argue that the positive contribution of online digital marketing tools use for loyalty on business performance satisfaction can be contingent on two factors. The first is the skill of the entrepreneur in the area of social competency. The second is whether or not the company generates most of its sales from online digital marketing tools. First, social competency refers to "the ability to interact effectively with others as based on discrete social skills" (Baron \&Markman, 2003, p. 41). In retail business, this competency involves various aspects, such as the ability to build good interpersonal relations with customers, to present the products to customers in an interesting and reliable manner, to communicate to customers with honesty, as well as to be enthusiastic in helping and sharing useful information with customers. Research has shown that individuals who exhibit good social competency tend to exhibit better performance in various areas (Belt et al., 2002; Hochwarter et al., 2006). In fact, social competency is also proposed as a crucial skill that strongly determines entrepreneurial success (Baron and Markman, 2000; Baron and Markman, 2003). Possessing these aspects of social competency can allow the SME Owners to develop good relationships with customers, which can increase customer satisfaction, and eventually benefit the business performance (Cheung and Tsang, 2005; Cron et al., 2005). Although possessing good social competency is important to help SME Owners develop good relationships with customers, which can eventually benefit the business, nevertheless a specific situation applies in the area of online digital marketing tools marketing. It is possible that SME Owners who exhibit lower social competency will have more opportunity to achieve better business performance when they use online digital marketing tools intensively for loyalty than those who already exhibit higher social competency. The suggestion that SME Owners who lack social competency tend to benefit more from using online digital marketing tools for loyalty can be explained by the social compensation hypothesis (Valkenburg, Schouten, \& Peter, 2005), which has been deployed in literature to explain some of the motivations for individuals' online digital marketing tools use. The social compensation hypothesis suggests that individuals who have difficulty developing friendships with other people in the real world are more motivated to use online digital marketing tools, because they can help substitute online contacts for an undesirable social network (Zywica \&Danowski, 2008). In particular, this role of online digital marketing tools communication is consistent with the media naturalness theory (Kock, 2004; Kock, 2005), which suggests that interaction that takes place through customer engagement tends to suppress key elements found in face-to-face communication (such as facial expressions, mood states, and body language), and this makes it difficult for a person to judge the real interpersonal skills of another person in customer engagement.Moreover, research has shown that the lack of nonverbal cues in customer engagement such as online digital marketing tools can help enhance communication performance, especially through impression management (Hogan, 2010 ;Krämer and Winter, 2008). This benefit of customer engagement can be explained by social information processing theory (Walther, 1992) and the social identification/de-individuation model (Lea \& Spears, 1992). First, the social information processing predicts that without nonverbal cues, communicators adapt their relational behaviors to the remaining cues available in customer engagement such as content and linguistic strategies, as well as chronemic and typographic cues (Walther, 1992; Walther, 1996). Second, the social identification/de-individuation model argues that the lack of nonverbal cues in online interaction prompts users to form impressions that are based on the social categories of communicators and not interpersonal cues (Lea \& Spears, 1992). In particular, Walther (1996) argued that visual anonymity is the key 
characteristic of customer engagement that allows users to construct a predominately positive impression that leads to idealized impressions of one's communication partner (Lea \& Spears, 1992). Studies also suggest that the absence of nonverbal cues also makes individuals more willing to disclose personal information when using customer engagement than in face-to-face interactions (Joinson, 2001).Generally, because social and communication skills are crucial for relationship-building in the business exchange (Baron \&Markman, 2000), the SME Owners who lack social skills tend to have more difficulty building good relationships with their customers when they interact face-to-face, when compared to those with better skills. However, because interacting with customers through online digital marketing tools tends to require less interpersonal skills than face-to-face interactions, SME Owners who lack good social skills can rely on online digital marketing tools interactions to enhance communication effectiveness. Without a nonverbal cue, customers are unable to detect true personality, style, and intention of the seller. Thus, using online digital marketing tools more intensively for loyalty is crucial to help this type of entrepreneur to form better impression with their customers in order to achieve better business performance. Given the benefits that online digital marketing tools provides, the authors predict that the social competency of the entrepreneur will negatively moderate the benefits of online digital marketing tools use for loyalty on business performance satisfaction. Lastly, the study proposes that the positive association between online digital marketing tools use for loyalty and business performance satisfaction will also depend on the degree to which companies' sales volumes mainly arise from online digital marketing tools sales. Specifically, the authors argue that the benefit of online digital marketing tools use for loyalty will be significantly higher for companies that have more sales volume from online digital marketing tools than those with more sales volume from physical stores. Essentially, companies that sell intensively on online digital marketing tools need to focus mainly on online digital marketing tools users as their target customers. Selling intensively on online digital marketing tools platforms implies that they will also face high competition from other sellers supplying similar products on online digital marketing tools. Thus, using online digital marketing tools for loyalty tends to be the most effective channel to help companies distinguish themselves from their competitors, because it provides the opportunity to deliver marketing messages to this target customer group more precisely and effectively; and this allows them to enhance customer satisfaction better than competitors who do not perform online digital marketing tools loyalty. The contribution of online digital marketing tools application to business performance for this group of companies can be explained by the resource-based view (RBV), which emphasizes the role of critical resources and capabilities that allow companies to achieve superior performance (Barney et al., 2001; Makadok, 2001). In particular, for companies that rely extensively on online digital marketing tools sales, the ability to deploy online digital marketing tools in relationship marketing is considered a unique competency of companies that enables them to provide superior services to customers (Ainin, Parveen, Moghavvemi, Jaafar, \&Shuib, 2015). Given that the business performance of companies that sell intensively on online digital marketing tools tends to depend strongly on the satisfaction of the online digital marketing tools customers, being able to enhance customer satisfaction through online digital marketing tools loyalty may be the most crucial marketing practice in enabling this group of companies to increase their business performance satisfaction. This prediction is also supported by prior research that found that the benefits of information technology (IT) capability on companies' performance tended to be more prominent in highIT-intensity companies than in low-IT-intensity ones (Ravichandran et al., 2005; Zhu and Kraemer, 2002).

\section{METHODS}

The sampling frame encompasses small shops located in seven major marketplaces in NCT, NCR, India. Because the focus of the study is online digital marketing tools use for loyalty, the respondents were pre-screened to make sure that they actually sold products on online digital marketing tools. A self-administered questionnaire survey was used for data collection. The questionnaires, along with a cover letter, were distributed in person to the owners of the shops at the marketplaces and were then collected in person by the authors. A total of 258 questionnaires was distributed and 220 questionnaires were returned, which accounts for an 85.27 percent response rate. Of this amount, three had not been properly answered, so they were removed. Overall, there were 217 completed surveys available for data analysis; none of them contained missing data.

Table 1 summarizes the descriptive statistics of the sample's characteristics. In particular, most of the sample firms were considered to be microenterprises which employed fewer than ten full-time employees. On average, more than half of their sales volume came from online digital marketing tools sales. The majority of the sample reported that they primarily sold on Facebook (86 percent), followed by Instagram (86 percent). Nonetheless, about half of the sample (49 percent) reported that they used both Facebook and Instagram to sell their products.

\begin{tabular}{|c|c|}
\hline Variables & Descriptive statistics \\
\hline \multirow{4}{*}{ Firm age (years) } & Mean: 2.86 \\
\hline & S.D.: 1.56 \\
\hline & Max: 1 \\
\hline & Min: 7 \\
\hline \multirow{4}{*}{$\begin{array}{l}\text { Firm size (number of } \\
\text { full-time employees) }\end{array}$} & Mean: 1.90 \\
\hline & S.D.: 0.78 \\
\hline & Max: 5 \\
\hline & Min: 1 \\
\hline \multirow{4}{*}{$\begin{array}{l}\text { Online digital marketing } \\
\text { tools experience in } \\
\text { business (years) }\end{array}$} & Mean: 2.16 \\
\hline & S.D.: 0.93 \\
\hline & Max: 5 \\
\hline & Min: 1 \\
\hline \multirow{4}{*}{$\begin{array}{l}\text { Online digital marketing } \\
\text { tools sales intensity } \\
\text { (percentage of online } \\
\text { digital marketing tools } \\
\text { sales to total sales) }\end{array}$} & Mean: 72.26 \\
\hline & S.D.: 16.29 \\
\hline & Max: 100 \\
\hline & Min: 20 \\
\hline \multirow{2}{*}{$\begin{array}{l}\text { Primary online digital } \\
\text { marketing tools used in } \\
\text { business }\end{array}$} & Facebook: 139 (64 percent) \\
\hline & Instagram: 78 (36 percent) \\
\hline $\begin{array}{l}\text { Number of online } \\
\text { digital marketing tools } \\
\text { sites used in business }\end{array}$ & $\begin{array}{l}\text { Only one online digital marketing tools site: } \\
50 \text { ( } 23 \text { percent) } \\
\text { More than one online digital marketing tools } \\
\text { site: } 167 \text { ( } 77 \text { percent })\end{array}$ \\
\hline \multirow{3}{*}{ Type of product sold } & $\begin{array}{l}\text { Clothing and accessories: } 168 \text { (77 percent) } \\
\text { Mobile phones and gadgets: } 21 \text { (10 percent) }\end{array}$ \\
\hline & $\begin{array}{l}\text { Foods and dietary supplements: } 12 \text { (6 percent) } \\
\text { Cosmetics: } 10 \text { ( } 5 \text { percent })\end{array}$ \\
\hline & Home decorations: 6 ( 3 percent) \\
\hline
\end{tabular}


All of the scales used to measure the concepts in the hypotheses were developed by the authors. The scale development was performed through a series of steps suggested by previous researchers (DeVellis, 1991; Netemeyer et al., 2003). A comprehensive item pool was generated from the literature review and an in-depth interview with a panel of marketing experts and business owners that had solid experience of online digital marketing tools marketing. The initial questions were sent to three marketing academics and fifteen SME Owners who had used online digital marketing tools in businesses, to help review the clarity and accuracy of the questions. The questions were then edited based on their suggestions. After the first draft of the questionnaire was created, the authors conducted a pre-test with 40 SME Owners to test the reliability and validity of the scales. The results from the pre-test showed satisfactory results. Online digital marketing tools use intensity for loyalty was measured by eight questions that encompassed four aspects of loyalty activities implemented through online digital marketing tools, comprising identification (two items), differentiation (two items), interaction (two items), and customization (two items). All items were rated on five-point Likert scale ranging from 1 (very little) to 5 (very extensive). Social competency was measured by six questions that were developed based on the review of prior research (Belt et al., 2002; Cheung and Tsang, 2005; Hochwarter et al., 2006). All items were rated on five-point Likert scale ranging from 1 (very little) to 5 (very extensive). Online digital marketing tools sales intensity was measured by simply asking the respondents to indicate the percentage of sales that their store generated from online digital marketing tools as compared to total sales. This method to measure firm transaction intensity has been widely used in previous research (e.g., Pla-Barber \& Alegre, 2007). Business performance satisfaction was measured by a self-rating scale, which has been widely adopted in previous research due to the difficulty of obtaining actual financial performance figures from small firms in developing countries (Calantone et al., 2006; Hashai, 2011). Using performance satisfaction is also appropriate for microenterprises because research has showed that they normally underreport financial outcomes (de Mel, McKenzie, $\&$ Woodruff, 2009). The respondents were asked to evaluate to what extent they were satisfied with their firm's performance in eight aspects. The items were rated on a fivepoint Likert scale ranging from 1 (very dissatisfied) to 5 (very satisfied).

In addition to the main independent variables presented in the hypotheses, the authors also controlled for firm-specific characteristics and some external factors that can influence business performance. Control variables represented by firms' characteristics include firm size (measured by the number of full-time employees) and firm age (measured by the number of years that the company has been established). In addition, the analysis also controlled for the effect of business competition intensity.
This variable was measured subjectively by asking the respondents to assess the intensity of the business competition that they encountered in three aspects; they were measured a five-point Likert scale ranging from 1 (strongly disagree) to 5 (strongly agree).

Regression was the statistical technique used for data analysis. Because the main constructs were measured as the reflective latent variables, it was important to test the reliability and validity of the constructs. A convergence validity test was conducted to assess factor loadings. All the factor loadings were above the 0.5 minimum requirement as suggested by Hair, Black, Babin, and Anderson (2010). A discriminant validity test was implemented by comparing whether the average variance was greater than the squared correlation coefficient (Fornell\&Larcker, 1981). The results, as presented in Table 2, show that all indicators satisfied this requirement. Construct reliability was estimated by Cronbach's alpha coefficient. The reliability indicators of all latent variables were higher than the minimum requirement of 0.7 (Nunnally, 1978). The result supports a positive relationship between online digital marketing tools use intensity for loyalty and business performance satisfaction $(\beta$ $=0.355 ; \mathrm{p}<0.001)$. The second column reports the results that include the moderating effect of social competency. It shows that the interaction term of online digital marketing tools use intensity for loyalty and social competency is negative and statistically significant $(\beta=-0.406 ; \mathrm{p}<0.001)$. The increase in the r-square suggests that the moderating effect of social competency explains the outcome variable by 13.1 percent additionally from the base model. The third column reports the results that include the moderating effect of online digital marketing tools sales intensity. It shows that the interaction term of online digital marketing tools use intensity for loyalty and online digital marketing tools sales intensity is positive and statistically significant $(\beta=0.244$; $p<$ 0.001). Also, the increase in the r-square suggests that the moderating effect of online digital marketing tools sales intensity further explains the outcome variable by 4.2 percent from the base model. The fourth column reports the results that include the moderating effect of social competency and online digital marketing tools sales intensity. The results are consistent with the previous findings. The interaction term of online digital marketing tools use intensity for loyalty and social competency is negative and statistically significant $(\beta=$ $-0.388 ; p<0.001$ ), while the interaction term of online digital marketing tools use intensity for loyalty and online digital marketing tools sales intensity is still positive and statistically significant $(\beta=0.151 ; p=0.004)$. The increase in the $r$-square suggests that the moderating effect of online digital marketing tools sales intensity further explains the outcome variable by 15.9 percent from the base model. Overall, the results from the final model still support Hypothesis 1, which predicts the positive association between online digital marketing tools use intensity for loyalty and business performance satisfaction $(\beta=0.185 ; \mathrm{p}<0.001)$.

\begin{tabular}{|c|c|c|c|c|c|c|c|c|c|}
\hline \multicolumn{10}{|l|}{ Regression } \\
\hline Variables Model & Model 2 & Model & Model 4 & & & & & & \\
\hline \multicolumn{4}{|c|}{ Online digital marketing tools use intensity for loyalty } & $0.355^{* * * *}$ & $0.204 * * *$ & $0.314 * * *$ & $0.185^{* * *}$ & & \\
\hline Social competency & $0.172 * *$ & $0.124 *$ & $0.197 * * *$ & $0.142 * *$ & & & & & \\
\hline \multicolumn{4}{|c|}{ Intensity of online digital marketing tools sales } & $-0.104 *$ & $-0.124 *$ & -0.075 & $-0.098^{*}$ & & \\
\hline \multicolumn{6}{|c|}{ Online digital marketing tools use intensity for loyalty $\times$ Social competency } & $\mathrm{n} / \mathrm{a}$ & $-0.406 * * * \mathrm{n} / \mathrm{a}$ & $-0.388 * * *$ & \\
\hline \multicolumn{8}{|c|}{ Online digital marketing tools use intensity for loyalty $\times$ Intensity of online digital marketing tools sales } & $\mathrm{n} / \mathrm{a}$ & $0.244^{* * *} \quad 0.151^{* *}$ \\
\hline
\end{tabular}


The results in the final model also support Hypothesis 2, which predicts the positive association between social competency and business performance satisfaction $(\beta=0.142$; $\mathrm{p}=0.006$ ). They also support Hypotheses 3 and 4, which predict the moderating effect of social competency and online digital marketing tools sales intensity respectively.

The present study explored the association between the intensity of online digital marketing tools use for loyalty and the business performance satisfaction of Thai microenterprises. In addition to the main effect of online digital marketing tools use for loyalty, the analysis also took into consideration the moderating roles of the SME Owners' social competency and the intensity of companies' online digital marketing tools sales. Overall, the results from PLS analysis supported all hypotheses proposed. First and foremost, the analysis showed that the SME Owners who used online digital marketing tools intensively for loyalty tended to report higher satisfaction with their business performance. In particular, the finding about the positive contribution of online digital marketing tools use for loyalty provides additional support to prior research, which had suggested that online digital marketing tools can serve as a channel for companies can implement loyalty in order to enhance business performance (Baird and Parasnis, 2011; Malthouse et al., 2013 ; Woodcock et al., 2011). This finding is also consistent with the recent empirical study of Trainor et al. (2014), which found the positive contribution of online digital marketing tools use to the performance of small and medium enterprises in Malaysia.

Furthermore, the results from the moderating effect analyses provided extra evidence that extends the findings of prior research. Interestingly, the analyses found that the positive relationship between online digital marketing tools use intensity for loyalty and business performance satisfaction appeared to be significantly higher for the SME Owners who exhibited lower levels of social competency in business. In particular, the finding about the higher positive contribution of online digital marketing tools use of this group of SME Owners is in line with the prediction suggested by the social compensation hypothesis (Valkenburg et al., 2005 ; Zywica and Danowski, 2008) and the media naturalness theory (Kock, 2004 ; Kock, 2005) that were mentioned in the beginning. Although the social compensation hypothesis was previously used to explain the benefits that individuals who have difficulty communicating with others in the real world can obtain from online digital marketing tools communication, this research shows that it can also be used to explain the benefits that the SME Owners who lack social competency might obtain when online digital marketing tools are used intensively to interact with the customers. In particular, this finding implies that online digital marketing tools interaction can be used as the channel that facilitates SME Owners who lack the social skills to develop face-to-face relationships with customers to compensate for this weakness. Given that communication in online digital marketing tools tends to involve less interpersonal interactions than face-to-face communication, using online digital marketing tools for loyalty activities tends to be essential in enabling SME Owners with low social competency to interact with customers to improve customer satisfaction.

In addition to the moderating role of the social competency of the SME Owners, the analysis further indicated that the positive contribution of online digital marketing tools use for loyalty was also significantly higher for the companies that generated more sales from online digital marketing tools. Generally, this finding implies that using online digital marketing tools for loyalty tends to be more crucial for companies that primarily target customers who are online digital marketing tools users. This finding confirms the importance of conducting loyalty activities on online digital marketing tools, as it can help companies that focus on online digital marketing tools customers to enhance their business performance.

Despite the contributions that the present study provides, the authors need to discuss some research limitations. First of all, the data used in the analysis were obtained from self-reported measures, which can be susceptible to subjective bias from the respondents. Second, the statistical analysis was performed by using cross-sectional data. Hence, the interpretation of the results can only be made in terms of correlations between constructs. Third, the study collected data from only a small portion of the microenterprise sample in the NCT area. In summary, this research has provided empirical evidence to support the importance of online digital marketing tools use for loyalty as being a marketing practice that can help microenterprises in NCR, India achieve higher business performance satisfaction. Overall, these findings offer additional contributions to the previous research that proposed the benefits of online digital marketing tools use in business, particularly in the area of loyalty. The study also filled the research gap by showing that the benefits that companies can obtain from online digital marketing tools use for loyalty can be contingent on some entrepreneur and firm characteristics. Lastly, the authors suggest that as more and more companies have begun to deploy online digital marketing tools in business to take advantage of the market opportunity presented by the increasing number of online digital marketing tools users, it is very important for firms, especially microenterprises, to learn to adapt online digital marketing tools for marketing purposes, in order to help them compete effectively in business.

\section{References}

Andrew, J. R and Vanitha, S. (2004). A typology of online shoppers based on shopping motivations, Journal of Business Research Vol. 57 PP. 748-757

Amit, B. Sanjoy, Ghose.(2004). A latent class segmentation analysis of e-shoppers, Journal of Business Research.Vol.57, PP.758-767.

Andrew, J. R \&Vanitha, S. (2004). A typology of online shoppers based on shopping motivations. Journal of Business Research. Vol. 57 (2004) PP.748- 757

Bell, E \& Bryman, A. 2007, Business research methods, New York: Oxford university press.

Boudraeu, M.C and Watson R.T (2006)."Internet Advertising Strategy Alignment" Internet Research. Vol.16 (1), PP.23-37

Cho and Jinsook. (2004). Likelihood to abort an online transaction: Influences from cognitive evaluations, attitudes, and behavioral variables. Information \& Management, Vol.41, PP. 827-838.

Creswell, J. (1994) Research design: Qualitative and quantitative approaches, London Press: Sage. 
Michael, R.S. Gary, B. Soren, A and Margaret, K.H.(2006).Consumer behavior: a European perspective, Financial Times/ Prentice Hall

Cuneyt, K. Gautam, B. (2004). The impacts of quickness, price, payment risk, and delivery issues on on-line shopping, Journal of Socio-Economics, Vol.33, PP.241-251.

Darian, J.C. (1987). In-Home Shopping: Are There Consumer Segments? Journal of Retailing, Vol.63,PP. 163-186.

Davis, F. D., Bagozzi, R. P. and Warshaw, P. R. (1989). User Acceptance of Computer Technology, journal of Management Science, Vol35 (8), PP.982-1003

DIBS Report (2010). "Full year report", online: http://www.ir.dibspayment.com/files/IR/uploadedFile s/eng/110307_dibsfull-yearreport2010.pdf, (Retrieved 2011-14-05).

Eccromania (2010)," Consumers: Online shopping increasingly popular in the EU, but development "held back" by barriers to cross border trade ", online: http://www.en.eccromania.ro/news/consumers-onlineshopping-increasingly-popular-in-the-eu-butdevelopment-held-back-by-barriers-to-cross-bordertrade, (Retrieved 2011-05-05).

Forsythe, S. M. and Shi, B. (2003).Consumer patronage and risk perceptions in internet shopping. Journal of Business Research, 56, PP. 867-875

France, B., Janine S. H. and Wanda J. S. (2002). Trustworthiness in electronic commerce: the role of privacy, security, and site attributes. Journal of Strategic Information Systems, Vol. 11, PP. 245-270.

Goldsmith, R. E. \& Bridges, E. (2000). Using attitudes to predict online buying behavior. Quarterly Journal of Electronic Commerce, 1, 245-253

Gurvinder, S. S and Zhaobin, C. (2005).Web-Based Shopping: Consumers' Attitudes towards Online Shopping in New Zealand, Journal of Electronic Commerce Research.Vol.6, No.2.

Hoffman, D.L., Kalsbeek, W.D., Novak, T.P., (1996).Internet and web Use in the United States.

Icek, A. (1991). The Theory of Planned Behavior: Organizational behavior and human resource processes. Vol50, PP.179-211.

Kim, J., Fiore, A. and Lee, H. (2007). Influences of online store perception, shopping enjoyment, and shopping involvement on consumer patronage behavior towards an online retailer, Journal of Retailing and Consumer Services Vol. 14 PP. 95-107

Joshua, G.(2001)The handbook of online marketing research: knowing your customer using the net,Newyork press: McGraw-Hill

Kehoe, C., Pitkow, J., Rogers, J.D. (1998).Ninth GVU's WWW user survey.

Kent, R. (2007) Marketing research approaches, methods and applications in Europe, Italy: rotolito printing

Kumar, R. (1996), Research Methodology- A Step by Step Guide for Beginners, Sage, London.

Liang, T. and Lai, H. (2000). ".Electronic store design and consumer choice: an empirical study”. Proceedings of the 33rd Hawaii International Conference on System Sciences,
Li, N. and Zhang P. (2002). "Consumer Online Shopping Attitudes and Behavior: An Assement Of Research". Eighth Americas Conference on Information Systems.

Loo, L.S. Sze, M.K. (2002). Singapore's Internet shoppers and their impact on traditional shopping patterns, Journal of Retailing and Consumer Services. Vol.9, PP. 115-124.

Michelle, A.M. and Brenda J. C. (2002). Consumer demand for online food retailing: is it really a supply side, International journal of retail and distribution management, Vol. 30, PP.451-458.

Michael, B. Mirta, G. and Tracy, T. (2007).Personality Determinants of online shopping: Explaining Online Purchase Intentions using a Hierarchical Approach, Journal of Business Research. PP 597-605.

Ming, H.H. (2009). Shopping mode choice: Physical store shopping versus e-shopping. PP.86-99

Narges, D., Laily, H. P. and Ali, K. (2009).Developing an Instrument for Measurement of Attitude toward Online Shopping. European Journal of Social Sciences, Vol. 7(3).

Neuman, W. L. (2000) Social research methods: Qualitative and quantitative approaches, Toronto: Allyn and Bacon.

Nik, K. Nik, M. and Siti, S. M. A. (2005)."Determinants Of Online Shopping". Proceeding Of International Conference On E-Commerce.

AcNielson Report (2005). "Global consumer attitudes towards online shopping", online: http://www.kr.en.nielsen.com/reports/GlobalConsume rReports.shtml, (Retrieved 2011-25-04).

Robinson, H., Riley, F.D., Rettie, R., \&Rolls,W, G. (2007). The role of situational variables in online grocery shopping in the UK. The Marketing Review,Vol 7(1), PP.89-106.

Robson, C. (1993). Real world research: a resource for social scientists and practitioner researchers.Cambridge, USA: Blakewell

Sami, A. (2002). Consumer Attitudes towards Online Shopping in Jordan: opportunities and challenges.

Saunders, M., Lewis, P. \& Thornhill, A. (2009) Research Methods for Business Students, Harlow: FT/Prentice Hall

Saunders, M.N.K., Lewis, P. and Thornhil, A. (2000), Research Methods for Business Students, Prentice Hall, London

Shahriar, A. and Masoud, J. (2010).Measuring e-shopping intention: An Iranian perspective. African Journal of Business Management, Vol. 4(13), PP. 2668-2675.

Syuhaily, O. B., Chan, Y.F. and Bei, H. C. (2010).Undergraduates and Online Purchasing Behavior. Asian Social Science, Vol. 6.

T. Hansen (2006) Determinants of Consumers' Repeat Online Buying of Groceries, Int. Rev. of Retail, Distribution and Consumer Research Vol. 16, No. 1, PP. $93-114$

UCLA internet report (2001)." Surveying the digital future", online: http://live.online.se/wip/ published archive/ucla-internet-2001.pdf, (Retrieved 2011-2102).

Thomson, S. H. T (2006). To buy or not to buy online: adopters and non-adopters of online shopping in 
Singapore, Behaviour \& Information Technology, Vol. 25, No. 6, PP. $497-509$

Mummalaneni, V. (2005). An empirical investigation of Web site characteristics, consumer emotional states and on-line shopping behaviors, Journal of Business Research Vol. 58 PP. 526-532

Webcheck (1999). "Marketing and selling to the South African web user", online: http://www.webckeck.co. za, (Retrieved 2011-25-03).

Xinyu, C. and Patricia L. M. (2005).The Intended and Actual Adoption of Online Purchasing.
Yasmin Hassan and Nik FadrizamAkiminAbdullah (2010) "Influencing Factors On Consumer Choice Towards Online Shopping",online: http://www.international conference.com.my/proceeding/2ndice2010_proceedi ng/ PAPER_ 086_Consumer Choice.pdf, (Retrieved 2011-04-22).

Zhang P, Von Dran G.M, Small R.V and Barcellos S, (1999) "Websites that Satisfy Users: A Theoretical Framework for Web User Interface Design and Evaluation". Proceedings of the 32nd Hawaii International Conference on System Sciences

Ziqi, $M$ and Tow, C.(2000). Internet-based e-shopping and consumer attitudes: an empirical study, Journal of Information \& Management. Vol.38, PP. 299-306.

\section{How to cite this article:}

Aparna P. Goyal (2017) 'Personalized Niche Online Marketing To Generate And Sustain E-Loyalty Among The Millennial Generation', International Journal of Current Advanced Research, 06(03), pp. 2421-2428. 